Association for Information Systems AIS Electronic Library (AISeL)

AMCIS 1999 Proceedings

Americas Conference on Information Systems

(AMCIS)

December 1999

\title{
Enterprise Resource Planning: A Business Approach To Systems Development
}

Sue Kelly

Manchester Business School, UK

Christopher Holland

Manchester Business School, UK

Ben Light

Follow this and additional works at: http:/ / aisel.aisnet.org/amcis 1999

\section{Recommended Citation}

Kelly, Sue; Holland, Christopher; and Light, Ben, "Enterprise Resource Planning: A Business Approach To Systems Development" (1999). AMCIS 1999 Proceedings. 271.

http://aisel.aisnet.org/amcis1999/271

This material is brought to you by the Americas Conference on Information Systems (AMCIS) at AIS Electronic Library (AISeL). It has been accepted for inclusion in AMCIS 1999 Proceedings by an authorized administrator of AIS Electronic Library (AISeL). For more information, please contact elibrary@aisnet.org. 


\section{Enterprise Resource Planning: A Business Approach To Systems Development

\author{
Sue Kelly, Dr. Chris Holland and Ben Light \\ Manchester Business School, Booth Street West, Manchester, M15 6PB, UK. \\ Email: s.kelly@fs2mbs.ac.uk Tel. +44 1612756460
}

Fax. +44 1612757134

\section{Introduction}

The problems associated with software development are widely recognised: projects finish late, cost more than originally predicted the resulting systems can be unreliable and difficult to maintain. Even if the information systems are technically sound, they often deliver disappointing organisational results (Hammer, 1990). ERP systems are sold on the basis that they can limit many of the risks associated with systems development and that the resulting system will be aligned with business requirements (Davenport, 1998). ERP systems are integrated software packages that automate core corporate activities such as finance, logistics and human resource management and have become the de facto standard in many industries throughout the nineties. This paper suggests that ERP systems have driven systems development into a new phase of maturity. It has taken several decades for the information systems profession and academics to identify that information systems need to be developed to meet business needs. However, with ERP system implementations this notion is reversed. Implementing an ERP system requires the organisation reengineer their business in line with the implicit 'best practice' business model contained within the system. The focus of the effort has shifted from a heavy weighting towards technical analysis and programming toward business process design and business focussed software configuration. The paper presents a theoretical framework based upon the results of eight international ERP projects, of which a sample of three are presented here. The framework explains how ERP projects represent a radically different approach to traditional systems development projects and aims to aid academic and management thinking in this important area.

\section{The Historical Context of Systems Development Methodologies}

Early applications of computers were generally implemented without a well-defined development methodology. The emphasis was placed on programming, rather than on design and only the technical aspects of development tended to be considered. Often, user needs were not properly established resulting in the misalignment of business requirements and information system capabilities (Avison and Fitzgerald 1995). Furthermore, the lack of formal software development methodologies sometimes caused projects to be years late and over budget. The resulting systems were also often unreliable, difficult to maintain and performed inadequately. The discipline of 'software engineering' then emerged in the late 1960s and a systems development life cycle (SDLC) was created which aimed guide the development process. The first SDLC was referred to as the 'waterfall model', because the development flowed from stage to stage - Analysis, Design Coding, Implementation and Maintenance (Boehm et. al. 1977). Numerous variations have been proposed since and an examination of the literature identifies three overlapping models or eras that dominated systems development thinking. The first, typified by Yourdon (1978), is essentially a technical approach. Then came organisationally focused approaches such as soft systems (Checkland 1981) and Business Process Reengineering/strategic approaches (Hammer 1990). Evidence from IT projects such as SNCF (Mitev 1998) and Chrysler (Mukhopadhyay et al 1995), and conceptual thinking, including Morton (1991), indicate that all of these approaches need to be considered during systems implementation. The ERP approach purports to offer this capability.

\section{The ERP Approach}

The ERP systems development approach is radically different from traditional SDLC approaches in several ways. The technical risk present when developing software is considerably reduced when choosing the ERP approach because companies can ensure that the ERP software which they are purchasing is technically sound and can provide the functionality they require. ERP systems offer common 'information blueprints' of organisations which typically cover $80 \%$ of an organisations business processes. Implementing an ERP system therefore leads to a finite set of solutions. In contrast, traditional SDLC methods offer infinite solutions as they aim to align a technology with the business. With ERP systems, organisations are forced to align their business processes with those dictated by the information blueprint of the package. The focus of the development process therefore shifts from writing software to understanding business processes. Systems design skills are still required, but the business content is much higher.

\section{The Theoretical Framework}


A framework for understanding why ERP implementation is different to traditional SDLC projects has been developed through theory building via case research (Eisenhardt 1989) and is presented in Figure 1. The framework provides a structure for analysing the case study data and understanding the inter-relationships between the separate theoretical constructs. The Business Environment is characterised by factors such as the emergence of globalisation, time-based competition and shorter product life cycles that impact on organisations. The Strategic Vision is the intended plan for transforming the organisation enabling it to operate in the new style environment. An evaluation of the current state of the business determines the Implementation Strategy. This centres around how the ERP system will be implemented, for instance, the implementation of a skeleton version of the system or the exploitation of the full functionality offered. Also addressed are issues such as project and change management. Business Process Design and

\section{Case 1: Threads}

\section{Case data}

\section{Business Environment and Strategic Vision}

Threads is part of a global group of companies with sites in 62 countries selling to consumer and industrial markets. The business comprises a large number of automonous business that have been acquired over a period of time. They manufacture and distribute sewing thread, hand knitting and consumer craft products and operate in a fiercely competitive global business environment. Manufacturing for fluctuating local markets and not taking advantage of economies of scale, the company suffered profitability problems throughout Europe. Thread's strategic vision aimed to maximize the benefits of international operations and ensure competitiveness through a focus on manufacturing excellence, customer service and cost effectiveness.

\section{Implementation Strategy}

The company decided to reengineer the organisation and this was supported by the implementation of a process oriented ERP solution. The implementation was based upon concensus throughout the business and involved exploiting the full functionality of the system. The scale of the change was a significant step shift for the organisation as, generally, the autonomous firms were not process-oriented.

\section{Business Process Design and Software Configuration}

The business radically reviewed the ways that it conducted its operations by developing macro level process ideas about the business and then taking them down to micro level in conjuction with the ERP package.
Software Configuration is concerned with aligning the existing business processes with those implicit within the ERP system.

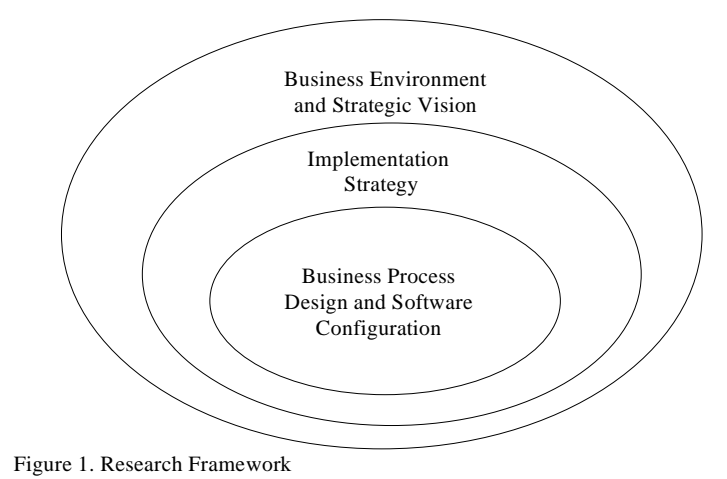

Threads then configured the ERP package to align with these processes.

Case 2. Comp Co.

Business Environment and Strategic Vision

Comp Co. is one of three autonomous but fully integrated groups of business and deliver complete network solutions for enterprise environments based on IBM, Digital, Hewlett Packard and Sun platforms. They are mid-range computer experts (an area of IT lying broadly between PC and mainframe systems) and have four divisions aligned around these manufacturers. Comp Co operates in a fiercely competitive and wished to become more customer focused by enhancing service and information to their customers. They also wanted to be in a position to change ahead of the market rather than behind it and provide alternative ways for customer's to access the company (i.e. via the Internet).

\section{Implementation Strategy}

Comp Co. needed to increase its customer focus but did not have the appropriate IT infrastructure. A skeleton implementation strategy was adopted and certain modifications to the software were made. The aim was to exploit the full functionality of the system when the core was complete. Although Comp Co. had to reengineer aspects of the business, it was expected that by implementing a skeleton system would reduce this effort and also the level of software configuration required leading to a relatively short initial implementation period and limited disruption to the business.

\section{Business Process Design and Software Configuration}

The ERP package vendors were able to map the system to the business. They demonstrated their software 
for a dummy company and this provided the basis for discussing different business process and software configuration options. As a result of these activities, some business processes were removed altogether and others changed. Action was taken to ensure that upgrades would not pose a problem in the light of the modifications. The implementation was completed in six months.

\section{Case 3 StatCo}

\section{Business Environment and Strategic Vision}

StatCo is a French company and a main supplier of office stationery in France. Statco's english subsidiary Offstat is now the largest stationery company in England. StatCo has been the subject of a number of mergers and acquisitions and now comprises a number of autonomous companies, each with their own IT system. Facing global competitive pressures, Offstat wishes to become the leading business in its market. It needed a common IT and business platform to support this vision.

\section{Implementation Strategy}

Offstat decided to provide each site with a system that matched or exceeded the functionality of its existing legacy system. When all of the sites were on the common platform they then aimed to implement the remaining functionality of the ERP package. Offstat chose not to carry out any bespoke development and staggered the implementation throughout the UK and Europe.

\section{Business Process Design and Software Configuration}

The existing business processes throughout all of the sites were aligned with the software package. The objective was to achieve 'generic' business processes and IT across the whole group. The implementation was relatively rapid and further functionality is being exploited now that the core is in place.

\section{Discussion of Case Data}

Faced with a fast changing business environment and infomation systems unable to meet their strategic vision, all three organisations decided to implement standard ERP packages. Both Comp Co. and StatCo adopted skeleton implementation strategies. StatCo made few changes to the software, reenginering their business in line with the 'information blueprint' implicit within the package. Comp Co. did make a number of modifications to the software. However, a number of these changes have been adopted by the vendors, who have incorporated these in upgrades of their product. Both of these implementations were fast-track and involved little disruption to the business. Threads, on the other hand, decided to adopt a full functionality implementation carrying out major reeingineering of their business. These radical changes proved difficult and time consuming. A move away from a systems development project using the traditional SDLC approach towards what we would term a systems implementation project was the case in all three companies. The focus was on extensive organisational analysis prior to selecting the package. The implementation was then mainly concerned with reeingineering business processes throughout the organisation in line with the business processes implicit within the software package and configuring the ERP package to align with these processes. Steps such as design and coding present in the traditional SDLC were are no longer a major component of the project implementation as these are carried out by the ERP vendor.

\section{Conclusions}

ERP systems embody an organisation structure, business processes and technical design and imply that companies share more similarities than differences. ERP systems contain an information blueprint of an organisation and force the organisation to focus on business process design. The organisations concluded that the technical risks generally associated with developing software were considerably reduced. However, risk during implementation associated with aligning the processes with those of the software package and the corresponding change management and software configuration was an issue. It is clear that companies need to consider the existing state of the business when choosing an ERP strategy given the impact that this can have upon the amount of business process design and software configuration during the project and ultimately its duration and outcome. Traditional SDLC systems development would fall into the centre of the framework as this is a purely technical approach with the emphasis on analysis and design. The implementation step is merely concerned with implementing the software and very rarely if ever involves business process reeingeering. The ERP systems development approach is concerned more with the implementation of the software package and the aligning of the business processes to the package.

\section{Acknowledgements}

The authors would like to thank the Engineering and Physical Sciences Research Council who have supported the research reported in this paper under the Systems Engineering For Business Process Change Programme of research.

\section{References}

References can be obtained from Sue Kelly on request. 